\title{
Analysis of Perceptions of Personnel at Organisational Levels on the Integration of Product, Functional and Process Orientations A Case Study
}

\author{
Ruth Sara Aguilar-Savén \\ Linköping Institute of Technology,Sweden, ruth.saven@ipe.liu.se
}

Abstract This paper presents a qualitative analysis undertaken in a large telecommunications company. The stimulus to this paper is to understand the beliefs and perceptions of company personnel of Enterprise Integration (EI). The research presented constitutes part of a wider project into EI within the company at one of its production facilities. The EI project studies a number of different aspects for the integration of product, functional and process orientations. This paper highlights some considerations for Enterprise Integration as a result of the analysis presented. The paper aims to enhance understanding of individual beliefs on EI in manufacturing companies.

\section{INTRODUCTION}

For enterprises in the manufacturing sector, their value adding processes are changing from a semi-stable state to a highly dynamic one. The result is a forthcoming era of continual change in their economic and technological environments. Coping with this continual change is the major future challenge. Enterprise Integration (EI) is seen by some people as one solution by which this could be accomplished.

Companies are traditionally divided into specialists within a hierarchical organisation, normally referred to as functions. As they become more "process orientated" they must overcome organisational boundaries to integrate the new process orientation into their existing functional organisation. Besides, more and more importance is given to the specific characteristics of products, leading to product-driven manufacturing e.g. focussing on the 
product life cycles. Thus, one may find companies dealing with three different ways of working at the same time: product orientation, functional orientation and process orientation. These companies need an effective way of integrating these three perspectives with a common understanding of the problem and a common language to communicate on this matter. What do employees and managers understand by these terms? What are the actual or perceived obstacles to achieve integration? What are suitable performance measures to ensure adequate integration?

This paper presents the answers to these questions. Beliefs and perceptions regarding "integration" among employees and managers at different hierarchical levels are analysed. Section 2 presents a description of the whole EI project carried out in the factory as a backdrop for the present analysis in order to understand the context of the interviews and their interpretation. Section 3 describes the methodology followed to accomplish the qualitative analysis. Section 4 shows the analysis as well as the main highlights of the present study. Finally, some conclusions, remarks and further research end the paper.

\section{BACKGROUND: CASE STUDY DESCRIPTION}

The case study is an EI project done in a large company into the telecommunications sector. The factory where the study was held has around 2.000 employees and is one of a number of production facilities within the company. The factory manufactures products for the Consumer market, which represents the most rapidly changing business segment for the whole company. New products are launched to the market continually with typical product life cycles of between 6 and 18 months. Flexibility, quick response, high efficiency and productivity are seen as some of the key success factors to enable the company to win order in the marketplace. These success factors lead the company, and specifically the factory under consideration, to focus on its processes and their relationship to its functional departments. Due to the short product life cycles the factory realises their importance in achieving the key success factors. New product introduction or product obsolescence affects many aspects of enterprise manufacturing decisions such as capacity, production processes, information system (IS), dedicated resources and operational responsibilities. Thus the company has three key considerations, defined as orientations, at this factory in the belief that they could achieve high operational and marketing benefits of working with them at the same time if they could ensure adequate alignment, i.e. integration. They think that a "tri-dimensional" approach might offer even higher benefits than simply the sum of each of the individual "dimensions". Nevertheless, to achieve 
their goal, an integrated manner of working among the three orientations is required. Integration means putting together the heterogeneous orientations to form a synergistic whole (similarly defined by Vernadat, 1996). It is not obvious how to achieve this last and specifically how the company's IS could support it. Furthermore the three perspectives have an effect on both the inter- and intra-organisational integration. Many detected conflicts when working together remain unsolved. Hence, the need for an EI project appeared. The goal of the project is to develop a generic model to explain and describe the integration between these orientations. The question to be answered: are the theories in the EI field adequate for this factory.

The literature on EI has been reviewed. There already exists a considerable amount of literature on the matter, explaining different emerging architectures and their related methodologies, concepts and tools; for example, Vernadat (1996) and Bernus, et al, (1996). Even comparisons between them (e.g. Kosanke, et al, 1997 or Bernus, et al, 1996) and great efforts to establish standards have been undertaken (e.g. ENV 40 003, 1990, ISO 15704, 1999 and ENV 12 204, 1995). A first drawback for the project when reviewing the literature on EI was that this concept has emerged from Computer Integrated Manufacturing (CIM) and thus the terminology utilised is often related to automation, automatic control and Computer Science resulting in difficulties when applying them in manufacturing. E.g. the term orientation was not found in the literature as managed in the company. Hence the need of deeper analysis of these and other terms and concepts, the integration from these orientations viewpoint and how they relate to the dimensions and views of GERAM, which is based on CIMOSA's cube. All this is further discussed in Savén (2002).

The orientations are defined as follows. Functional orientation (FO) is a way of working organised in departmental areas each of which group homogeneous functions highly specialised. This is the traditional approach and reflects the current organisational structure. Process orientation (PsO) is a way of working focused on the identification of important work's flow. A process is a collection of activities that take one or more kinds of inputs and create an output of value to the customer. Product orientation (PtO) is the way of working in which all operational issues regarding the product are followed during its life cycle on a global basis to ensure that they are carried out in a consistent, effective manner, promoting integration between all parties involved with the product.

Despite a number of meetings held in order to let managers and other employees know of the EI project during its first months, the author of this paper realised that still different people at the factory have different perceptions of EI. Specifically the term EI seems to be quite vague for the majority of employees. Words such as dimensions or views are found to have varied 
interpretations or even sometimes treated as synonymous. Hence the need emerges to solve these communication problems.

\section{METHODOLOGY}

Bearing in mind that the qualitative study was one part in a larger case study its purpose was to get an understanding of the perceptions, difficulties and contradictions in employees' mental models that prevent EI development and from them to be able to improve EI approaches including associated theories, methods, techniques and tools. At the same time an unexpected but welcome output of the study was to aid employees to achieve a shared vision and understanding of EI in order to contribute in the EI project.

According to Trost, (1997) if the aim of a research study is to understand the way people reason and/or to establish common patterns in the way they perceive matters, as in this paper, then a qualitative approach is recommended. There are three general steps in the process of either a qualitative or quantitative study: data gathering, data analysis and interpretation of the results. The combination of these three steps and the consideration of the study type form what is called the "property space" (Trost, 2001). According to Trost there are 8 study variants. The study described in this paper is classified as variant $\mathrm{A}$, which is a complete qualitative analysis. This means that data collection; analysis and the interpretation of the results are qualitative in their nature.

The data collection is based on interview questionnaires. The sample is chosen non-randomly using the technique known as strategic sampling (Trost, 2001). The idea is to choose the sample in such a way that one may find variations of the answers from those who are interviewed according to relevant variables or categories. Of course this sample is statistically nonrepresentative but perfectly valid for qualitative analysis. The first step in the method employed is to define the variable that has the most significant theoretical meaning. This was established as the organisation's hierarchical level. Four hierarchical levels are defined: strategic management, tactical management, operational management and operational. Next another variable is found relevant: the orientation in which the interviewees are working in i.e. process, product or functional orientation. Finally, if interviewees are technical or non-technical educated is the last category under consideration although later on this is found non relevant. Hence the sample is chosen to select individuals covering all possible combinations of these variables.

The individuals to be interviewed are selected based on the snowball method. That is, the first person in interviewed during which that person is asked who is the person(s) he or she considers the most appropriate to be 
interviewed next to cover the categories considered. Then the interviewer does the next interview according to this suggestion and thus the interviewer proceeds so forth until the whole sample is covered.

The first interviewee was the site's top manager who suggested that himself and those above him in the organisation should be considered as strategic management. In this category most of those who are related to the factory under analysis were interviewed. The top manager also considered that all managers in the next level under him formed what is defined as tactical management and thus most of them were interviewed. Some tactical managers suggested some of the operational managers to be interviewed and these suggested a number of operators. When selecting among those suggested persons it was considered whether they were technicians or not as well as their involvement in the orientations always bearing in mind to cover as many variants as possible from these variables

It was important too to take into account the idea of creating a work group that would support the EI project. The objective is to establish a work group for the author to work with in which consists of people from different departments, levels, orientations, and type of education with the purpose of getting information, competence and experience to accomplish the EI project. A total of 22 interviews were carried out from February to April 2001. On average each of them lasted around $1.5 \mathrm{hrs}$. For each interview firstly the questionnaire was sent by internal post together with a covering letter explaining the reasons and goals of the survey. In this way the interviewee could think about the questions. The questionnaire is standardised in the sense that its focus is one subject: EI and it is based on open questions. Secondly, phone calls were made to get an appointment for the interview and make sure that the interviewees wanted to help. This last is found very delicate for the validity of the interview since the company was passing across a critical situation and the confidence on the interviewer is of the major importance. Finally, the interviews were carried out bearing in mind the conditions needed for its reliability (Trost, 1997).

The data analysis is presented in next section as well as the interpretation of the results. For the validity of the findings some meetings with some of the managers at different levels were performed.

\section{DATA ANALYSIS AND FINDINGS OF THE STUDY}

Before starting the description of the analysis it is worth mentioning that because of limitations in the length of this paper only some of the main findings are presented. As a starting point the percentage distribution of interviewees per category is shown in Table 1 . Although there is a strong desire 
to integrate the three orientations defined the study showed that the perception at the factory is that they feel that they are working $100 \%$ only as FO and partially in the other two orientations. People think these last orientations either are working inefficiently or do not exist at all: "...we try but we cannot reach them yet", "... we have some flows but not a process oriented enterprise" (see Table 2).

Table 1: Distribution of interviewees' category in percentage.

\begin{tabular}{|l|l|c|}
\hline Category & Subcategory & Interviewees (\%) \\
\hline \multirow{4}{*}{ Hierarchical level } & Strategic management & 23 \\
& Tactical management & 27 \\
& Operational management & 23 \\
& Operational & 27 \\
Orientation & Involved in Functional & 45 \\
& Involved in Process & 18 \\
Education type & Involved in Product & 36 \\
& Technicians & 82 \\
& Non-technicians & 18 \\
\hline
\end{tabular}

Table 2: Interviewees' affirmative perception in percentage of the orientation's existences at the factory.

\begin{tabular}{|l|c|c|c|}
\hline \multirow{2}{*}{\multicolumn{1}{c|}{ Subcategory }} & \multicolumn{3}{|c|}{ Orientation } \\
\cline { 2 - 4 } & Functional & Process & Product \\
\hline Strategic management & 100 & 50 & 50 \\
Tactical management & 100 & 60 & 60 \\
Operational management & 100 & 70 & 60 \\
Operational & 100 & 75 & 62 \\
Involved in Functional & 100 & 50 & 55 \\
Involved in Process & 100 & 71 & 43 \\
Involved in Product & 100 & 100 & 100 \\
Technicians & 100 & 69 & 61 \\
Non-technicians & 100 & 75 & 61 \\
All & 100 & 70 & 62 \\
\hline
\end{tabular}

Concerning the need of working with the three orientations at the same time 21 of the 22 interviewees $(95 \%)$ recognised such a need: "...yes, we need them be cause they complement each other". Only one person doubted that FO helps. When trying to understand in which way they complement each other is four categories of answers resulted: $19 \%$ find them necessary because they each have a different strategic focus " ...they support in different way the missions and visions of the company". $40 \%$ find the need due to organisational focus with arguments as: "...it is a natural way to distribute responsibilities" or "...decisions must be taken with different criteria". $32 \%$ think that orientations have different control focus: "... they control in medium and long term: products, markets, resources and procedures". Finally, 
9\% stated other reasons such as: “...well, technically they are different and thus must exist".

However, Table 3 shows that FO is not seen as an important orientation at any level. PtO is the most important for higher hierarchical levels while for lower levels the PsO is perceived as the most important. This may be explained by the fact that $\mathrm{PtO}$ is closely related to the market place and thus has a strong strategic component while $\mathrm{PsO}$ is related to operational matters. Only one fifth of the interviewees find all orientations equally important.

Table 3: The most important orientation in percentage of interviewees

\begin{tabular}{|l|c|c|c|c|}
\hline & \multicolumn{4}{|c|}{ Orientation } \\
\cline { 1 - 5 } Subcategory & \multirow{2}{*}{ Functional } & Process & Product & All three \\
Strategic management & & & 80 & 20 \\
Tactical management & & 33 & 50 & 17 \\
Operational management & & 60 & 20 & 20 \\
Operational & & 83 & 17 & \\
All hierarchical levels & 0 & 46 & 36 & 18 \\
\hline
\end{tabular}

When looking for means to integrate the orientations answers are categorised as those related to the: Information System (IS), Organisation, Technology, Mindset/attitudes and Strategies



Figure 1: Means to integrate the answers on orientations

as Fig. 1 shows. When splitting the answers according to hierarchical levels it is found that Mind-set was pointed out at all levels, Organisation is pointed out mainly at higher levels while $I S$ at lower levels. It is important to mention as well that Technology is perceived as a means to integration only in $5 \%$ of the cases.

Using the same categorisation for the obstacles, which prevent the integration of the orientations, it is found that those related to Organisation are the ones most pointed out with $29 \%$ (see Fig. 2), followed by those related to Strategies, IS and Mind-set with $21.5 \%, 19 \%$ and $17 \%$ respectively. Technology represents now a higher percentage with $13.5 \%$. When splitting them 
according to levels: higher levels see obstacles mainly in the Organisation and Strategies while lower levels in all of them.

Concerning what the performance measurements are to assure the integration among the three orientations the following was found:

- At all hierarchical levels the company's key performance indicators

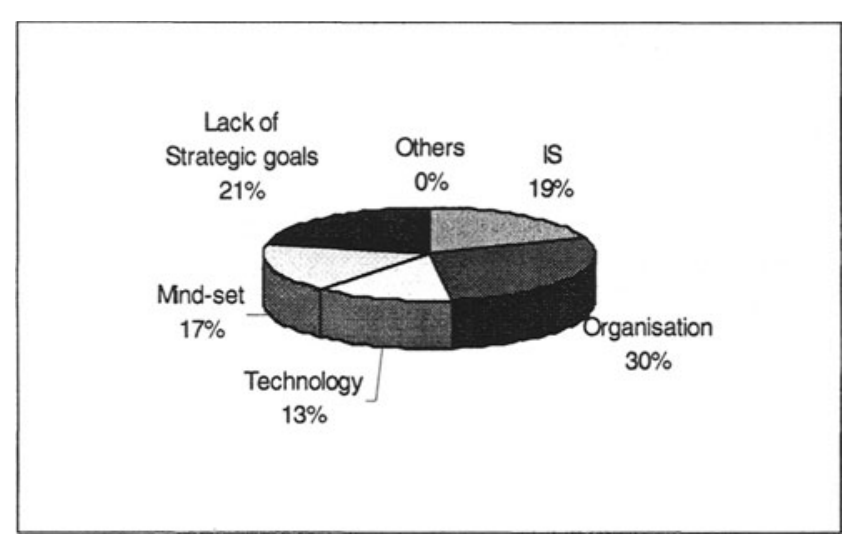

Figure 2: Ohstacles to integration

(KPI) are basically considered global indicators of the performance and thus show degree of integration.

- Profits, production yield (percentage of products that are okay) and shipment accuracy (number of orders delivery on time) are mentioned by $90 \%$ of the interviewees.

- At low hierarchical levels more importance were given to technical performance measurements such as quality or it surrogate scrap (volume of defective products), blocked invoices (number of invoices blocked due to quality problems when products were delivered to customers), production or utilisation (occupied capacity or load) while tactical and strategic levels focused on financial measurements as profits/losses and costs.

- Other specific indicators must be settled in order to measure both strategic goals for the whole company as well as those per function, process and/or product. A comparison between the planned indicator's values versus the real performance's values is necessary to be done.

- A proposal to control the performance of each orientation is through the cost: cost per function, cost per product and cost per process (planned cost versus real cost).

\section{CONCLUSIONS}

There is a clear contrast between what the managers of the enterprise define as ways of working and the perceptions of employees who are actually working within the enterprise. While the enterprise managers may suggest 
certain working models for the employees the employees themselves do not find such models the easiest to implement, operate and manage. Many of the declared models of EI have concentrated on the technological aspects of implementation. This study has highlighted the possibility that organisation aspects, such as people's mind- have a significant role to play. This study indicates that new EI models need to be developed and tested that explicitly addresses these non-technical issues.

People's mind-set/attitudes is seen as the main means to integrate an enterprise although an adequate organisational structure, effective IS and appropriate business strategies are also necessary. Technology is seen more as an obstacle to achieving integration rather than a means to attaining it. This establishes a future research agenda for developing, verifying and validating new EI models.

FO is found important only in relation to the other orientations but not in itself. It is seen as the one that supports the other two taking some decisions or certain responsibilities over the others when necessary. However, $\mathrm{PsO}$ is seen as being essential to accomplish operations efficiently while PtO is having its importance based on its strategic nature. PtO uses the other two orientations and might modify them. Therefore all three orientations complement each other and hence it is relevant to research their integration. The integration of the three orientations may use traditional global performance indicators as a means to assess its accomplishment. However, other more specific indicators need to be established.

\section{REFERENCES}

Bernus P, Nemes L. and Williams T. (1996), Architectures for Enterprise Integration, Chapman \& Hall.

ENV 40003 (1990), Computer integrated manufacturing - systems architecture - framework for enterprise modelling, CEN/CENELEC TC310/WG1.

ENV 12204 (1995), Advanced manufacturing technology - systems architecture - constructs for enterprise modelling, CEN/CENELEC TC310/WG1.

ISO/DIS 15704 (1999), Requirements for enterprise reference architectures and methodologies, ISO TC 184 SC5/WG1.

Kosanke K. and Nell J.G. (Eds.) (1997), Enterprise Engineering and Integration: Building International Consensus, Springer-Verlag.

Savén R. (2002), Integration of Product, Process and Functional orientations: principles and a case study, Paper submitted to APMS 2002, The International Conference on Advanced Production Management System, 8-13 September, Eindhoven, The Netherlands.

Trost J. (1997), Qualitative interviews, Lund: Studentlitteratur, Sweden.

Trost J. (2001), The questionnaire book, Lund: Studentlitteratur, $2^{\text {nd }}$ ed., Sweden.

Vernadat, F. (1996), Enterprise Modelling and Integration - Principles and Applications, Chapman \& Hall. 